\title{
068 RECRUITMENT, PLACEMENT AND TRANSFER POLICIES AND PRACTICES FOR GOVERNMENT DOCTORS IN INDIA: ARE THEY PEOPLE CENTRIC?
}

Bhaskar Alok Purohit, 1 Tim M Martineau. ' $P$ PHFI, Ahmedabad, India; '2 Liverpool School of Tropical Medeciene, Liverpool, United Kingdom

\subsection{6/bmjopen-2015-forum2015abstracts.68}

Background Many countries face the challenge of inadequate number of doctors, their inequitable distribution and poor motivation among the doctors to join rural health centres that lead to health service provider's dissatisfaction, absenteeism and poor health system responsiveness. One of the main reasons for poor responsiveness of the health systems and providers is the weak, sometimes non-existent and often non people centric Human Resource (HR) policies and practices. While there is an increasing interest among researchers about the HR issues and how it is linked to systems abuse, there is limited research focusing on whether $\mathrm{HR}$ policies and systems relating to Recruitment, Placement and Transfer are pro doctors/employees or not? The present study is very important and covers crosscutting issues related to governance, corruption and Human resource for Health $(\mathrm{HRH})$ and includes a topic which is of global relevance.

Objectives To identify the actual policies and practices relating to Recruitment, Placement and Transfer for Government Doctors in India and to find out the gaps, if any, between actual policies and practices in order for Health Systems to be more people centric and for better Human Resource Management. Methods The study aimed at identifying the existing recruitment, placement and transfer policies and actual practices for Government Medical Officers (MOs) from one state in India. The analysis is based on document review to understand the existing policies, 24 in-depth interviews with MOs and five interviews with Key Informants to understand HR policies and their actual implementation, and Job histories to understand various HR processes like recruitment, frequencies of transfer and the reasons for transfers. Thematic framework approach was used to analyze qualitative data using NVIVO.

Result While the state has general recruitment and transfer guidelines that are applicable to all government department and officers including the MOs, there is no specific recruitment and transfer policy for health department and MOs. The state also does not have any placement related policy. In particular the transfer guidelines are poorly implemented at ground indicating a big gap between actual policy and implementation. The results also suggest systems abuse in form of political influence that has a great influence over MOs willingness to join and continue 
service with rural government health centres. The overall placement and transfer system is considered to be erratic and unfair. The recruitment process is also considered to be very sporadic in nature. The overall implementation of $\mathrm{HR}$ policies and systems was considered to be ineffective by the study respondents.

Conclusion The HR policies and practices in the state are not people centric and as result contribute to MOs dissatisfaction. The state should have a separate Recruitment, Placement and Transfer policy for MOs as the needs for Health Department are different from needs of other government departments. MOs interest and motivation must be central when formulating such policies. Equally important is to ensure that such policies are implemented in essence to address the issue of systems abuse and to prevent dissatisfaction of MOs so that quality care could be provided to the people. 